\title{
Danos do percevejo barriga-verde Dichelops melacanthus (Dallas) (Heteroptera: Pentatomidae) em trigo
}

\author{
Damage of the green belly stink bug Dichelops melacanthus \\ (Dallas) (Heteroptera: Pentatomidae) to wheat
}

\author{
Silvana Manfredi-Coimbra ${ }^{1}$ Jovenil José da Silva ${ }^{2}$ Viviane Ribeiro Chocorosqui $^{3}$ \\ Antônio Ricardo Panizzi ${ }^{4}$
}

\section{RESUMO}

O objetivo deste estudo foi avaliar a reação de dois cultivares de trigo aos danos causados por percevejos adultos de Dichelops melacanthus (Dallas), confinados sobre a cultura a partir do início do perfilhamento. Foram comparados os efeitos de diferentes níveis de infestação $(0,2$, 4, 8 e 16 percevejos $\mathrm{m}^{-2}$ ) sobre o número de perfilhos $\mathrm{m}^{-2}$, número de espigas $\mathrm{m}^{-2}$, peso de mil sementes $(\mathrm{g})$ e rendimento ( $k g \mathrm{ha}^{-1}$ ) das cultivares ' $B R$ 18' e 'BRS 193' de trigo, em Londrina, $P R$. O número de perfilhos $\mathrm{m}^{-2}$ cresceu linearmente para a $\mathrm{cV}$. 'BR 18' e de forma quadrática para a $\mathrm{cV}$. ' $B R S$ 193' com o aumento do número de percevejos $\mathrm{m}^{-2}$ o número de espigas $\mathrm{m}^{-2}$, o peso de mil sementes, e o réndimento decresceram de forma linear com o aumento do nível de infestação para as duas cultivares. 'Acv.BRS 193' foi mais suscetível ao ataque de D. melacanthus, apresentando uma redução de $254,4 \mathrm{~kg}$ para cada unidade de aumento no número de percevejos $\mathrm{m}^{-2}$.

Palavras-chave: Insecta, plantio direto, rendimento, nível de infestação.

\section{ABSTRACT}

The objective of this study was to evaluate the reaction of two cultivars of wheat to the damage caused by adults of the green belly stink bug, Dichelops melacanthus (Dallas), confined on the culture from the beginning of tillering. The effect of different infestation levels $(0,2,4,8$ and 16 bugs $\mathrm{m}^{-2}$ ) on the number of tillers $\mathrm{m}^{-2}$, number of spikes $\mathrm{m}^{-2}$, weight of 1,000 seeds $(\mathrm{g})$, and yield $\left(\mathrm{kg} \mathrm{ha}^{-1}\right)$ was evaluated on wheat cvs. 'BR 18' and 'BRS 193', in Londrina,
Paraná State. The number of tillers $m^{-2}$ increased linearly on ' $B R$ 18' and in a quadratic form on 'BRS 193', with the increase of the number of bugs $\mathrm{m}^{-2}$; the number of spikes $\mathrm{m}^{-2}$, the weight of 1,000 seeds, and the yield decreased linearly with the increase of the infestation level on both cultivars. 'BRS 193' was the most susceptible to the attack of $\boldsymbol{D}$. melacanthus, showing a reduction of $254.4 \mathrm{~kg}$ for each unit of increase in the number of bugs $\mathrm{m}^{-2}$.

Key words: Insecta, no till, yield, infestation level.

\section{INTRODUÇÃO}

As mudanças no cenário agrícola decorrentes do sistema de plantio direto e do cultivo no período da chamada "safrinha" têm propiciado o estabelecimento de diversos insetos-praga (CHOCOROSQUI \& PANIZZI, 2004). Dentre eles, o percevejo barriga-verde, Dichelops melacanthus (Dallas), ataca as culturas do milho, Zea mays L., e do trigo, Triticum aestivum L., na fase inicial de desenvolvimento, especialmente no Paraná (PANIZZI, 1997). Nesse Estado, o cultivo do milho "safrinha” após a colheita da soja ou do milho, e a utilização da mesma área para cultivo do trigo no inverno, fornecem condições ideais para a sobrevivência de insetos polífagos, como o $\boldsymbol{D}$. melacanthus, cuja população aumenta a ponto de

\footnotetext{
${ }^{1}$ Curso de Pós-graduação em Fitossanidade, Universidade Federal de Pelotas. Rua Mal. Deodoro, 713/305, 96020-220, Pelotas, RS, Brasil. E-mail: silvana.coimbra@pop.com.br. Autor para correspondência.

${ }^{2}$ Curso de Ciências Biológicas, Centro Universitário Filadélfia (UniFil), Londrina, PR, Brasil.

${ }^{3}$ Ministério da Agricultura, Londrina, PR, Brasil. E-mail: viviane.ribeiro@agricultura.gov.br.

${ }^{4}$ Empresa Brasileira de Pesquisa Agropecuária, Centro Nacional de Pesquisa da Soja, Londrina, PR, Brasil. E-mail:

panizzi@cnpso.embrapa.br
} 
causar danos significativos em diversas culturas (CHOCOROSQUI, 2001).

Na cultura do trigo, em 1995 ocorreram as primeiras observações desse pentatomídeo no Paraná, na região Oeste do Estado; em 1998 ocorreu em várias outras regiões, e em 1999, atingiu níveis populacionais altos de forma generalizada no Estado (CHOCOROSQUI, 2001). Ninfas e adultos são encontrados sobre o solo, próximos à base das plantas ou sob os restos culturais da soja, e estão associados ao sistema de plantio direto, o qual fornece abrigo e alimento, resultando em crescimento populacional (PANIZZI \& CHOCOROSQUI, 2000). Sua ocorrência tem sido observada desde a implantação da cultura do trigo até o espigamento, sendo que a fase mais suscetível ao ataque de percevejos na cultura vai do emborrachamento ao espigamento (GASSEN, 1983; 1984). Segundo CHOCOROSQUI \& PANIZZI (2004), todas as fases de desenvolvimento do trigo são suscetíveis ao ataque de $\boldsymbol{D}$. melacanthus, porém a maior redução do rendimento ocorre devido à ação dos mesmos do alongamento dos caules (26,5\%) ao estágio de grão leitoso (33,1\%).

Os danos qualitativos em trigo seguem uma seqüência de eventos, que se inicia com pontuações transversais, evoluindo para necrose, enrolamento e/ ou secamento da parte da folha acima das pontuações, além da formação de perfilhos anormais causando o sintoma de “cebolinha”, caracterizado pela não separação das folhas (CHOCOROSQUI, 2001). Os danos quantitativos ocasionados pela a alimentação do percevejo barriga-verde em trigo não foram ainda determinados.

O objetivo do trabalho foi quantificar os danos causados por diferentes níveis populacionais de D. melacanthus nos cultivares de trigo 'BR 18' e 'BRS 193', através da estimativa dos componentes de rendimento da cultura.

\section{MATERIAL E MÉTODOS}

O experimento foi instalado em junho de 2001, na área experimental da Embrapa Soja, em Londrina, Paraná (latitude $23^{\circ} 55^{\prime} 45^{\prime}$ 'S). Os danos de D. melacanthus em trigo, submetidos a diferentes níveis de infestação, foram avaliados através dos componentes do rendimento das cvs. 'BR 18' e 'BRS 193’, selecionadas por serem cultivadas numa área representativa da região de estudo. As duas cultivares foram semeadas na densidade de 120 plantas $\mathrm{m}^{-2}$, seguindo as recomendações de cultivo para a cultura.

No início do perfilhamento do trigo, quatro gaiolas teladas $(1,0 \times 1,0 \times 1,0 \mathrm{~m})$ estruturadas com armação de ferro foram montadas sobre as plantas de cada cultivar, para cada nível populacional do percevejo, que constou de 0, 2, 4, 8 e 16 percevejos adultos $\mathrm{m}^{-2}$. Os percevejos utilizados nesse experimento foram coletados a campo em plantas hospedeiras alternativas, levados ao laboratório e mantidos em caixas gerbox a $25 \pm 1^{\circ} \mathrm{C}, 65 \pm 5 \%$ de UR e fotofase de 14 horas, por um período de 24 horas sem alimentação. Posteriormente, foram liberados no interior das gaiolas os diferentes níveis de infestação, os quais não foram substituídos.

Foram avaliadas as seguintes variáveis: número de perfilhos $\mathrm{m}^{-2}$, número de espigas $\mathrm{m}^{-2}$, peso de mil sementes (g) e rendimento $\left(\mathrm{kg} \mathrm{ha}^{-1}\right)$. O delineamento experimental foi inteiramente casualizado com quatro repetições, sendo os dados submetidos à análise de variância em nível de 1\% de probabilidade para verificação do efeito de cultivar, nível de infestação e da interação cultivar*infestação. Posteriormente, foram ajustadas equações de regressão para cada variável resposta. No caso de ocorrência de interação significativa entre cultivar e infestação, ajustou-se para cada cultivar, separadamente, um modelo matemático, utilizando-se o programa estatístico SAS (LITTELL et al., 1996).

\section{RESULTADOS E DISCUSSÃO}

O efeito da interação cultivar*infestação para as variáveis número de perfilhos $\mathrm{m}^{-2}$ e rendimento foi significativo pelo teste F.

O número de perfilhos $\mathrm{m}^{-2}$ cresceu linearmente com o aumento do número de percevejos $\mathrm{m}^{-2}$ para a cv. 'BR 18' (Figura 1). Esta parece ser uma resposta fisiológica da planta que ocorre em muitas espécies as quais apresentam a capacidade de suportar o ataque da praga através da emissão de novos ramos ou perfilhos, ou por outro meio qualquer, de forma que o ataque não chegue a provocar queda significativa na qualidade e quantidade de sua produção (LARA, 1991).

Tanto a cv. 'BR 18' quanto a cv. 'BRS 193' apresentaram uma resposta compensatória à injeção de saliva por D. melacanthus no momento da alimentação. Entretanto, a cv. 'BRS 193' respondeu à infestação de forma quadrática com relação ao perfilhamento, havendo pequena redução no número de perfilhos $\mathrm{m}^{-2}$ inicialmente, e, a partir de quatro percevejos $\mathrm{m}^{-2}$, houve aumento no número de perfilhos, que variou de 5 a $35 \%$, quando os níveis de infestação foram de 4 e 16 percevejos $\mathrm{m}^{-2}$, respectivamente (Figura 2). Já para a cv. 'BR 18', este aumento foi de aproximadamente $11 \%$ com quatro percevejos $\mathrm{m}^{-2}$, e de $20 \%$ com 16 percevejos $\mathrm{m}^{-2}$. 


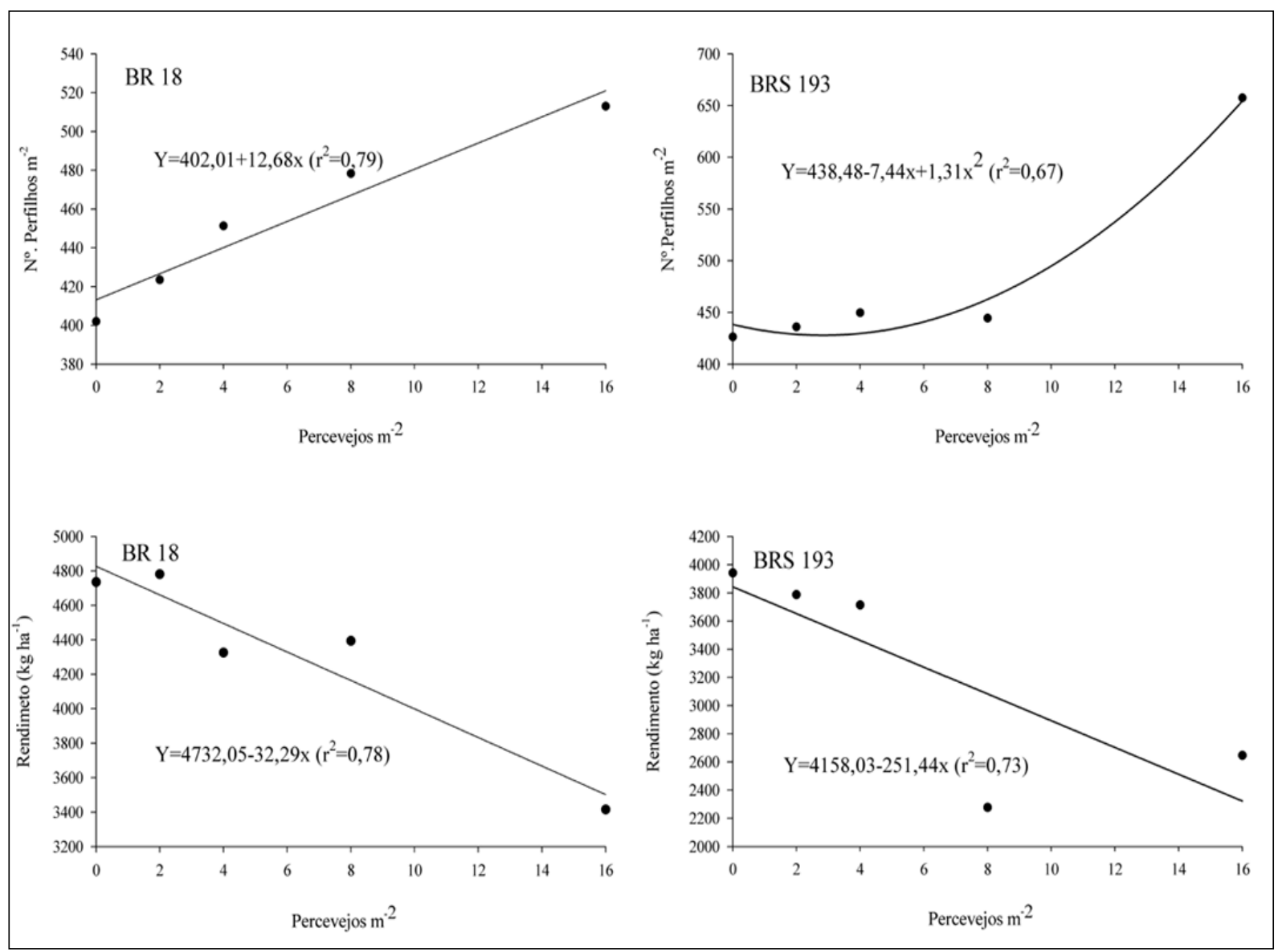

Figura 1 - Curvas de regressão ajustadas para os componentes do rendimento número de perfilhos $\mathrm{m}^{-2}$ e rendimento das cultivares 'BR 18' e 'BRS 193' infestadas com 0, 2, 4, 8 e 16 adultos de Dichelops melacanthus m $^{-2}$. Londrina, 2001.

A interação cultivar*infestação para a variável número de espigas $\mathrm{m}^{-2}$ não foi significativa, portanto as duas cultivares responderam da mesma forma à infestação com relação a esta variável. O aumento do número de perfilhos não resultou, entretanto, em aumento no número de espigas $\mathrm{m}^{-2} \mathrm{como}$ era de se esperar; ao contrário, a relação entre o número de perfilhos $\mathrm{m}^{-2}$ e os níveis de infestação foi linear, porém decrescente (Figura 2). Isto implica dizer que a planta, possivelmente, utilizou suas reservas para produção de perfilhos $\mathrm{m}^{-2}$ debilitados e este foi o fator limitante para emissão de espigas.

Ambos cultivares tiveram uma redução de 17,5 espigas $\mathrm{m}^{-2}$ para cada nível de infestação aumentado (Figura 2), o que, teoricamente, iria afetar o rendimento final da cultura, tendo em vista que o mesmo está altamente correlacionado com componente número de espigas.

Normalmente, os percevejos fitófagos se alimentam de sementes, por isso são comumente associados a plantas em período reprodutivo. Porém, na ausência de plantas normalmente utilizadas como alimento os percevejos podem utilizar outras plantas ou partes menos preferidas, como estruturas vegetativas (PANIZZI \& CHOCOROSQUI, 2000). Este comportamento foi exibido por $D$. melacanthus na condição de confinamento e de ausência de outras plantas hospedeiras, e vem sendo observado a campo, quando a soja não está disponível, inclusive na presença de outras espécies hospedeiras.

A alimentação do percevejo barriga-verde durante a fase de perfilhamento do trigo tem um efeito direto sobre o espigamento. Segundo CHOCOROSQUI (2001), há um percentual de espigas chochas de 3,2\% quando o ataque ocorre no perfilhamento e de acordo com PANIZZI \& CHOCOROSQUI (2000) e CHOCOROSQUI \& PANIZZI (2004), quando não é realizado o tratamento de sementes em área de plantio direto, a redução média do número de espigas é de cerca de 34\%.

Ciência Rural, v.35, n.6, nov-dez, 2005. 


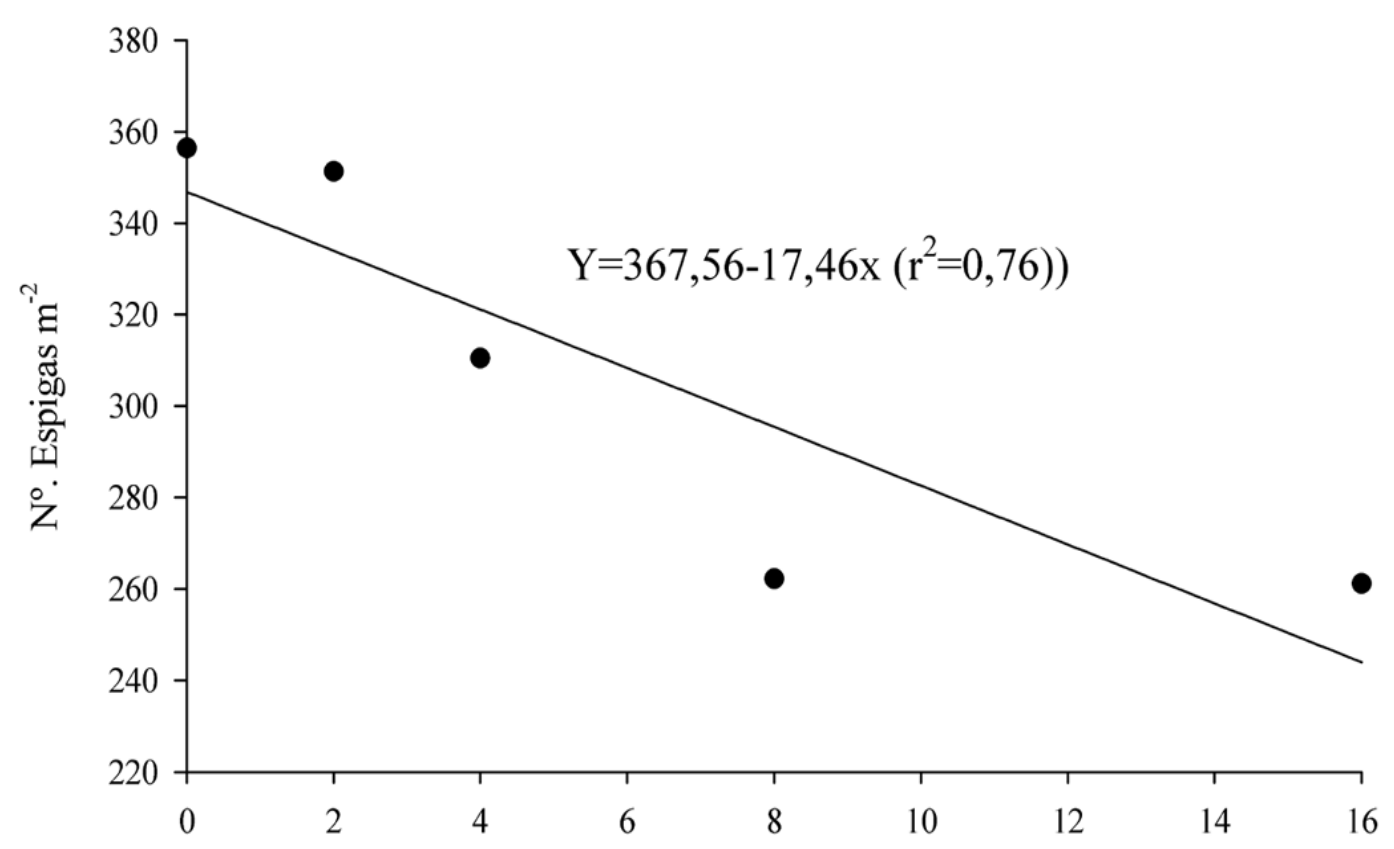

Percevejos $\mathrm{m}^{-2}$

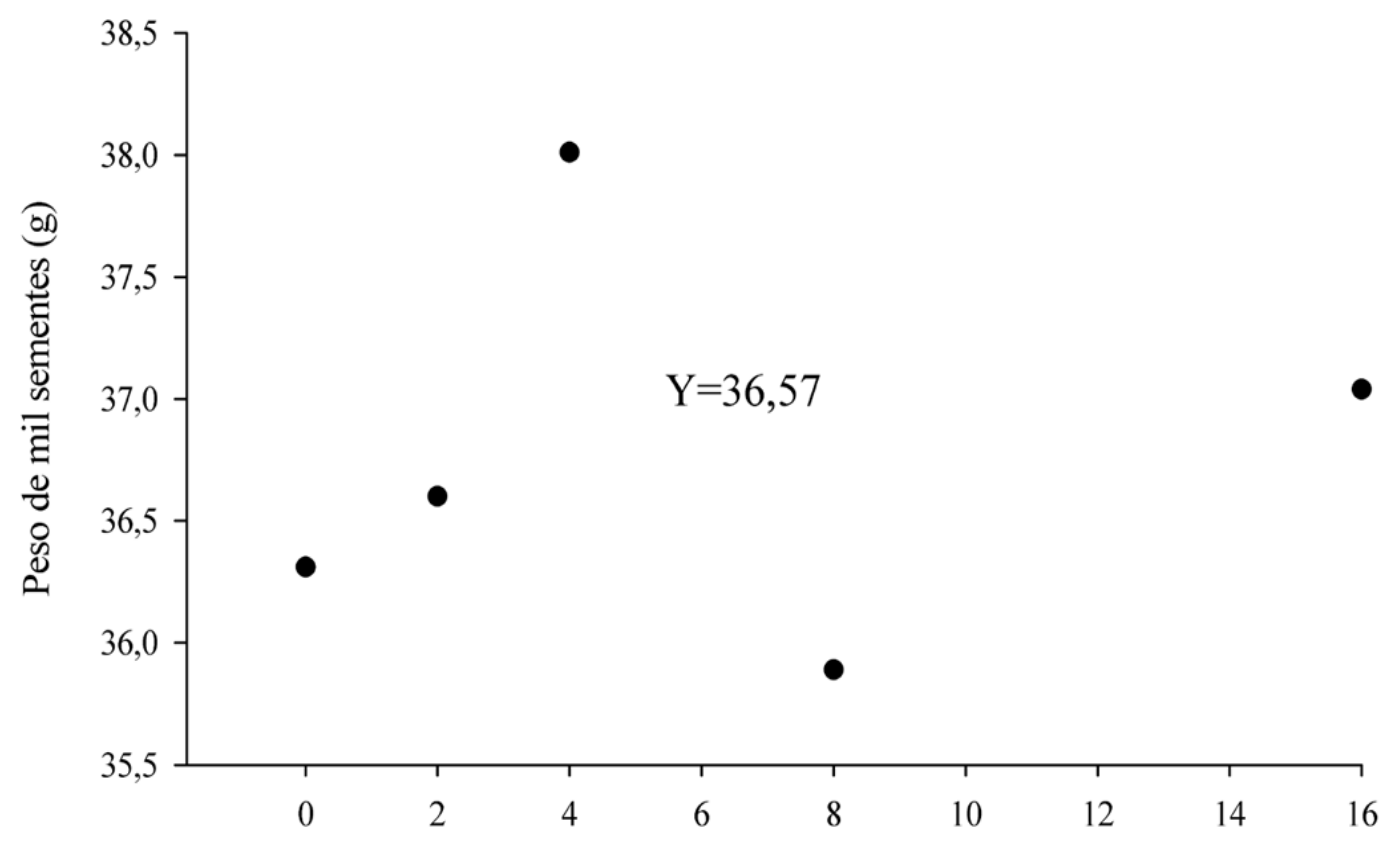

Percevejos $\mathrm{m}^{-2}$

Figura 2 - Curvas de regressão ajustadas para os componentes do rendimento número de espigas $\mathrm{m}^{-2}$ e peso de mil sementes (g) de cultivares de trigo infestadas com 0, 2, 4, 8 e 16 adultos de Dichelops melacanthus $\mathrm{m}^{-2}$. Londrina, 2001.

Ciência Rural, v.35, n.6, nov-dez, 2005. 
Ambos cultivares tiveram também o peso de mil sementes afetado de forma similar. Não foi possível ajustar equação linear ou quadrática para este componente do rendimento, e a equação está representada apenas pelo valor médio obtido para as cultivares entre os diferentes níveis de infestação (Figura 2). Segundo CHOCOROSQUI \& PANIZZI (2004) o ataque de $\boldsymbol{D}$. melacanthus em plântulas de trigo no plantio direto ocasionou redução no peso de grãos de $31 \%$.

A decomposição dos graus de liberdade do fator rendimento para a cV. 'BR 18' mostrou significância para o componente linear, de modo que nas condições experimentais, para cada aumento de uma unidade no nível populacional do percevejo barriga-verde, ocorreu uma redução de $32,3 \mathrm{~kg} \mathrm{ha}^{-1}$, ou seja, um percevejo $\mathrm{m}^{-2}$ é capaz de provocar redução de mais de meia saca de trigo por hectare e ainda, sob infestação de 16 percevejos $\mathrm{m}^{-2}$, essa redução é de cerca de $27 \%$ do rendimento comparativamente às plantas não infestadas (Figura 1). PANIZZI \& CHOCOROSQUI (2000) registraram uma redução de cerca de $30 \%$ no rendimento do trigo quando não foi efetuado controle químico de percevejos.

Entre as muitas estruturas das plantas, as sementes compreendem o principal sítio de alimentação de pentatomídeos, onde os nutrientes são mais facilmente obtidos (SLANSKY \& PANIZZI, 1987), e o peso de sementes e o rendimento são diretamente influenciados pela capacidade da planta de enviar nutrientes para estruturas reprodutivas. CHOCOROSQUI (2001) estudou o efeito da alimentação de percevejos sobre o rendimento da cV 'BR 18' infestada nos diferentes estágios de desenvolvimento da cultura, e foi observado que a menor redução da produção ocorreu quando as plantas foram infestadas durante o perfilhamento, e ainda assim, ocasionaram uma redução de 7,3\% em comparação às plantas não infestadas.

A equação de regressão que melhor representou a reação das cultivares, quando submetidas aos diferentes níveis populacionais de $\boldsymbol{D}$. melacanthus, foi uma equação polinomial linear. Há indicativos de que a cv. 'BR 18' suporta mais o ataque do percevejo barriga-verde, uma vez que seu rendimento médio (4.732 $\left.\mathrm{kg} \mathrm{ha}^{-1}\right)$, além de ser maior do que o da cv. 'BRS 193', tem uma redução casual de rendimento com o ataque de percevejos por apresentar o “b” não significativo. Acv. 'BRS 193’, além de ter um rendimento médio menor, apresenta uma redução significativa de $251,4 \mathrm{~kg}$ para cada unidade de aumento no nível de infestação de $\boldsymbol{D}$. melacanthus. Logo, no momento da escolha das cultivares a serem semeadas, especialmente em áreas com histórico de ocorrência do percevejo barriga-verde, deve-se dar preferência para a cv. 'BR 18'.

\section{CONCLUSÃO}

Nas condições desse estudo, é possível concluir que os danos do percevejo barriga-verde, Dichelops melacanthus, são menores sobre a cv. 'BR 18' do que a cv. 'BRS 193', uma vez que o rendimento da cv. BRS 193 reduziu significativamente na presença do inseto.

\section{REFERÊNCIAS}

CHOCOROSQUI, V.R. Bioecologia de espécies de Dichelops (Diceraeus) (Heteroptera: Pentatomidae) e danos em soja, milho e trigo no Norte do Paraná. 2001. 158f. Tese (Doutorado em Entomologia) - Universidade Federal do Paraná.

CHOCOROSQUI, V.R.; PANIZZI, A.R. Impact of cultivation systems on Dichelops melacanthus (Dallas) (Heteroptera: Pentatomidae) populations and damage and its chemical control on wheat. Neotrop Entomol, Londrina, v.33, n.4, p.487-492, 2004

GASSEN, D.N. Manejo integrado de pragas do trigo. Inf Agrop, Passo Fundo, n.9, p.47-49, 1983.

GASSEN, D.N. Insetos associados à cultura do trigo no Brasil. Passo Fundo: Embrapa CNPT, 1984. 39p. (Circular Técnica, 3).

LARA, F.M. Princípios de resistência de plantas a insetos. São Paulo: Ícone, 1991. 336p.

LITTELL, R.C. et al. SAS system for mixed models. Cary: Statistical Analysis System Institute, 1996. 633p.

PANIZZI, A.R. Entomofauna changes with soybean expansion in Brazil. In: NAPOMPETH, B. (ed.). WORLD SOYBEAN RESEARCH CONFERENCE 5., 1997, Bankok. Proceedings... Bangkok: Kasetsart University, 1997. p.166168.

PANIZZI, A.R.; CHOCOROSQUI, V.R. Os percevejos inimigos. A Granja, Porto Alegre, n.616, p.40-42, 2000.

SLANSKY JR., F.; PANIZZI, A.R. Nutritional ecology of seed-sucking insects. In: SLANSKY, JR.; RODRIGUEZ, J.G. Nutritional ecology of insects, mites, spiders and related invertebrates. New York: Wiley, 1987. Cap.3, p.283-320. 